University of Windsor

Scholarship at UWindsor

Mechanical, Automotive \& Materials

Department of Mechanical, Automotive \& Engineering Publications

Materials Engineering

3-2011

\title{
Optimal production planning for a multi-product closed loop system with uncertain demand and return
}

\author{
Jianmai Shi \\ Guoqing Zhang \\ University of Windsor \\ Jichang Sha
}

Follow this and additional works at: https://scholar.uwindsor.ca/mechanicalengpub

Part of the Business Administration, Management, and Operations Commons, Environmental Engineering Commons, Industrial Engineering Commons, Management Sciences and Quantitative Methods Commons, and the Operations and Supply Chain Management Commons

\section{Recommended Citation}

Shi, Jianmai; Zhang, Guoqing; and Sha, Jichang. (2011). Optimal production planning for a multi-product closed loop system with uncertain demand and return. Computers \& Operations Research, 38 (3), 641-650.

https://scholar.uwindsor.ca/mechanicalengpub/15

This Article is brought to you for free and open access by the Department of Mechanical, Automotive \& Materials Engineering at Scholarship at UWindsor. It has been accepted for inclusion in Mechanical, Automotive \& Materials Engineering Publications by an authorized administrator of Scholarship at UWindsor. For more information, please contact scholarship@uwindsor.ca. 


\title{
Optimal production planning for a multi-product closed loop system with uncertain demand and return
}

\author{
Jianmai Shi ${ }^{\text {a,b }}$, Guoqing Zhang ${ }^{\mathrm{a}^{*}}$, Jichang Sha ${ }^{\mathrm{b}}$ \\ ${ }^{a}$ Department of Industrial and Manufacturing Systems Engineering, University of Windsor, Windsor, \\ Ontario, Canada \\ ${ }^{\mathrm{b}}$ School of Information System and Management, National University of Defense Technology, \\ Changsha, Hunan, China
}

*Corresponding author. Email: gzhang@uwindsor.ca

\begin{abstract}
We study the production planning problem for a multi-product closed loop system, in which the manufacturer has two channels for supplying products: producing brand-new products and remanufacturing returns into as-new ones. In the remanufacturing process, used products are bought back and remanufactured into as-new products which are sold together with the brand-new ones. The demands for all the products are uncertain, and their returns are uncertain and price-sensitive. The problem is to maximize the manufacturer's expected profit by jointly determining the production quantities of brand-new products, the quantities of remanufactured products and the acquisition prices of the used products, subject to a capacity constraint. A mathematical model is presented to formulate the problem and a Lagrangian relaxation based approach is developed to solve the problem. Numerical examples are presented to illustrate the model and test the solution approach. Computational results show that the proposed approach is highly promising for solving the problems. The sensitivity analysis is also conducted to generate managerial insights.
\end{abstract}

Keywords: closed loop supply chain; uncertain demand; uncertain return; reverse logistics 


\title{
Optimal production planning for a multi-product closed loop system with uncertain demand and return
}

\author{
Jianmai Shi ${ }^{\text {a,b }}$, Guoqing Zhang ${ }^{\mathrm{a}^{*}}$, Jichang Sha ${ }^{\mathrm{b}}$ \\ ${ }^{a}$ Department of Industrial and Manufacturing Systems Engineering, University of Windsor, Windsor, \\ Ontario, Canada \\ ${ }^{\mathrm{b}}$ School of Information System and Management, National University of Defense Technology, \\ Changsha, Hunan, China
}

*Corresponding author. Email: gzhang@uwindsor.ca

\begin{abstract}
We study the production planning problem for a multi-product closed loop system, in which the manufacturer has two channels for supplying products: producing brand-new products and remanufacturing returns into as-new ones. In the remanufacturing process, used products are bought back and remanufactured into as-new products which are sold together with the brand-new ones. The demands for all the products are uncertain, and their returns are uncertain and price-sensitive. The problem is to maximize the manufacturer's expected profit by jointly determining the production quantities of brand-new products, the quantities of remanufactured products and the acquisition prices of the used products, subject to a capacity constraint. A mathematical model is presented to formulate the problem and a Lagrangian relaxation based approach is developed to solve the problem. Numerical examples are presented to illustrate the model and test the solution approach. Computational results show that the proposed approach is highly promising for solving the problems. The sensitivity analysis is also conducted to generate managerial insights.
\end{abstract}

Keywords: closed loop supply chain; uncertain demand; uncertain return; reverse logistics

\section{Introduction}

Closed loop supply chain (CLSC) has attracted growing attention in recent years due to the increased environmental concerns, government legislations and awareness of natural resource limitation in worldwide. Hundreds of articles on this topic have been published on main operations and management journals (Rubio et al. 2008). Closed loop supply chain has also widely practiced in industry. In U.S. more than 73,000 firms participate in CLSC, and act some functions related with 
remanufacturing (Guide et al. 2000).

In many industries, original equipment manufacturers (OEMs) actively participate in the remanufacturing business. Because OEMs have more knowledge on products and markets, they can operate the manufacturing and remanufacturing activities together and optimize the value of the whole closed loop system. For example, Kodak collects the used single-use camera from customers for reusing (Aras et al. 2006), and similar remanufacturing strategies also can be found for the OEMs of many products, such as photocopier (Van der Laan et al. 1999), printer, electronic machine, toner cartridge and automobile part (Aras et al. 2006, Kim et al. 2006). By remanufacturing used products and bringing them back to the market, not only the environmental and customers benefit, OEMs could also reduce their production cost.

OEMs face many new challenges to their production planning when they build up and operate the closed loop system. First, the original manufacturer has two channels to satisfy the demands: manufacturing brand-new products by new raw materials and components, and remanufacturing returns into as new ones by reusing the components with good function and replacing the worn out components. Second, both the demand and the return are uncertain, thus the manufacturer has to face two types of overstocking and understocking risks: new products and returned products. Third, the capacity for the manufacturing and remanufacturing is usually limited. It is difficult to determine the optimal allocation policy for the limited capacity. Additionally, the quality and timing of the return are also quite uncertain, which has been observed by many investigations. Guide and Van Wassenhove (2001) point out that used product acquisition management may serve as a foundation tool to control the return flow. They suggest manufacturers positively acquire used products, so as to reduce the uncertainties on quality, quantity, and timing.

We investigate a production planning problem for a multi-product closed loop system where the original manufacturer takes charge of brand-new products manufacturing, used products buying back, and remanufacturing. The manufacturer has the power to determine the acquisition price for the used products, and only buys back the used products that can be remanufactured. The return quantity of the used products is assumed to be price-sensitive and uncertain. The remanufactured products have no difference from the brand-new products and can be sold at the same market with the same price. We present a mathematical model to maximize the expected profit of the entire system, which simultaneously determines the production quantity of the brand-new products, the 
acquisition price of the used products, and the quantity of the remanufactured products. Then a solution approach is developed based on the Lagrangian relaxation method.

The proposed problem is a single-period production planning problem for a closed loop system with both demand and return uncertainty. Both production quantity decision and remanufacturing quantity decision are the kind of newsvendor problem, and made at the beginning of the planning period. For the remanufacturing part, the return horizon is from the beginning of the planning period to the end of remanufacturing. This also makes our study much different from most other production planning problems for a closed loop system in the current literature, which usually determine the production quantity after the return has been obtained. We investigate this problem based on the following observation: for many products with relatively short life cycles, such as single-use cameras, copy/print cartridges, computers, the recoverable value from these used products is time-sensitive, that is, the longer the used product returns are delayed in the recoverable inventory during the active market demand period, the less value can be recovered through remanufacturing. Guide et al. (2006) investigate the time value of commercial product returns through two practical closed loop supply chain. Their analysis show that processing returns faster may provide more profit for the remanufacturing system when the value of returns easily erodes away because of processing delays. Atasu and Çetinkaya (2006) study the lot sizing problem of remanufacturing system, and also emphasize on the fact that timing is critical under finite life cycles.

To the best of our knowledge, it is the first investigation in the literature that integrates used product acquisition decisions into the production planning problem for the closed loop system. Although this integration brings more challenges, it makes the optimization problem more practical. Because the reverse flow of the returns and the forward production flow are coordinately optimized, and more profit of the system could be gained.

An outline of the paper is as follows. In Section 2, a brief review of related research is presented. The model formulation is presented in Section 3, and a solution approach based on the Lagrangian relaxation is developed in Section 4. The computational results and managerial analysis are reported in Section 5. We finally conclude the paper in Section 6. 


\section{Literature review}

Various strategic and operational aspects of CLSC have been investigated in the last decades, such as forecasting, production planning/control, inventory control/management, and location. Our study is to optimize the profit of the closed loop system by integrating three aspects, that is, used product acquisition management, production, and inventory control.

When manufacturing and remanufacturing operations are both involved in the closed loop supply chain, the coordination between the two production processes is a crucial challenge to the manufacturer. Van Der Laan et al. (1999) study the production planning and inventory control problem for a closed loop system where manufacturing and remanufacturing operations occur simultaneously. All the products produced by the manufacturing process and the remanufacturing process can be used to fulfill customer demands. Two control strategies are analyzed: the PUSH strategy where all returned products are remanufactured as early as possible; and the PULL strategy where all returned products are remanufactured as late as it is convenient. Inderfurth (2004) analyzes the optimal policies to control a hybrid manufacturing/remanufacturing system, where brand-new products can be used to substitute the remanufactured ones in case of a shortage of remanufactured products.

Zhou et al. (2006) investigate a hybrid manufacturing and remanufacturing system. By control theory and simulation, the dynamic performance of the hybrid system is analyzed. Aras et al. (2006) present a modeling framework for a hybrid manufacturing and remanufacturing system, and analyze the prioritization and coordination strategies for replenishing serviceable products. Kim et al. (2006) develop a multi-period, multi-product mixed integer programming model for a supply planning problem, in which returned products are disassembled to remanufacture. In the system, the manufacturer has two alternative options for the parts supplying: either ordering them from external suppliers or overhauling the used products and bringing their parts back to 'as new' conditions. Licekens and Vandaele (2007) extend a facility-location mixed integer linear programming model in a reverse logistics context with queueing relationships. The extension is particularly relevant for time sensitive products with a high value. Listes (2007) proposes a generic stochastic model for design of networks comprising both supply and return channels organized in a closed-loop system, and presents a decomposition approach to solve the problem based on the integer L-shaped method. 
Choi et al. (2007) present a joint EOQ and EPQ model for an inventory control problem in a closed loop system, in which the demand can be satisfied by purchasing brand-new products and remanufacturing used products. Rubio and Corominas (2008) investigate a reverse logistics system when it is operated in a lean production environment. They analyze the coordination of capacity between manufacturing and remanufacturing, and develop the optimal production policies of the system.

In the closed loop system, the manufacturer not only has to coordinate the production process, he also has to consider the balance between the uncertain demand and the uncertain return. After investigating the production planning and control activities at remanufacturing firms in U.S., Guide (2000) identifies seven complicating characteristics of the remanufacturing system. The first two of them are balancing return with demand and uncertainties in timing, quality and quantity of returns. Fleischmann et al. (2002) present a systematic analysis on the inventory control problem for a closed loop system, where the demand and return are assumed to be independent and follow the Poisson processes. Fleischmann and Kuik (2003) study an inventory control model and examine the impact of product return flow on inventory management. Through the Markov decision processes, it is shown that an $(s, S)$ policy is optimal to minimize the long-run average cost. From a managerial point of view, Inderfurth (2005) analyzes the challenges to the product recovery management in a closed loop system and points out that production, recovery and disposal decisions often have to be balanced under considerable uncertainties of demand and return.

Guide and Van Wassenhove (2001) present a framework to analyze the potential economic attractiveness of remanufacturing. Analysis results show that it is better to positively acquire used products according to their quality, and used product acquisition management may serve as a foundation tool to control the return flow. Guide et al. (2003) further present a framework for a remanufacturing system, where the quantity and quality of returns depend on the acquisition price of used products. An application from cellular telephone industry is used to illustrate the framework.

Bakal and Akcali (2006) investigate an end-of-life product remanufacturing system in automotive industry, in which the return and demand are assumed to be price-sensitive and deterministic. They consider the random yield and develop models to optimize the acquisition price of end-of-life products and the selling price of the remanufactured parts. Dobos and Richter (2006) 
study an integrated production-recycling problem for a reverse system that minimizes the total EOQ and non-EOQ related costs. Their study shows that it is better for the manufacturer to only acquire the reusable products. Jayaraman (2006) investigate a closed loop supply chain in which the used products are acquired according to their quality, and present an analytical approach to optimize the production planning and control of the system. Qu and Williams (2008) present a nonlinear programming formulation for the automotive reverse production planning and pricing problem, in which the quantity of used products follows a function of the buying back price. Based on the manufacturing cost and the anticipated future sale prices of the remanufactured products, Liang et al. (2009) present a model to evaluate the acquisition price of the used products.

Used product acquisition management has been widely recognized as an efficient tool to control the uncertainties of the quality, quantity and timing of the return flow. But there still needs a further investigation on how to integrate it with production planning or other activities in closed loop supply chain.

More than 180 articles on CLSC are published within the period 1995-2005 (Rubio et al. 2008). From a system perspective, the closed loop system contains inputs, processes, structure and outputs, all of which have been studied separately (Pokharel and Mutha 2009). CLSC has grown up from solving isolated OR subproblems and become an important research area in operations research and management field (Guide and Van Wassenhove 2009). But most current mathematical models about CLSC are deterministic, and not enough attention has been paid to the stochastic nature of demand and returns (Pokharel and Mutha 2009). By coordinating CLSC's key drivers in a systematic way, an integration model is needed and crucial for maximizing the profitability of CLSC. The problem becomes very complex when several aspects of the system are integrated, such as the management of the return flow, the coordination between the manufacturing and remanufacturing, the balance between the return and demand. Thus developing an efficient solution approach for the integrated model is important, as more value and profit can be obtained when it is optimized in an integrated way.

\section{Model formulation}

The manufacturer produces multiple products through a flexible facility that involves both 
manufacturing and remanufacturing processes. In the remanufacturing process, used products are bought back from product holders and stocked in the recoverable inventory. Then used products are sent to the production facility from the recoverable inventory according to the remanufacturing order. In the facility, returned products are dissembled and inspected, and the components with good function are reused directly while the components with lower quality are repaired or replaced. After the remanufacturing process, returned products are remanufactured into as-new products and stocked in the serviceable inventory. The remanufactured products usually are not enough to satisfy the demands, thus brand-new products also are produced through the manufacturing process. We can see that the manufacturer operates a multi-product closed loop system where two production processes (manufacturing and remanufacturing) and two inventories (recoverable and serviceable) are included. This is a typical hybrid manufacturing and remanufacturing system, and similar systems are also investigated by Van Der Laan et al. (1999), Aras et al. (2006), Kim et al. (2006), Georgiadis et al. (2006), and Choi et al. (2007). Since both the demand and the return are uncertain, the manufacturer encounters more understocking and overstocking risks.

\subsection{Assumptions}

The following assumptions are made to develop the model.

- There is no distinction between the brand-new product and the remanufactured product, and they are sold together at the same market with the same price (Van Der Laan et al. 1999, Aras et al 2006).

- All returns are remanufacturable (Van Der Laan et al. 1999, Liang et al. 2009).

- The demands for the multiple products are uncertain and independent of each other.

- The return horizon is from the beginning of the planning period to the end of remanufacturing, and the return quantity is price-sensitive and stochastic. The relationship between the return quantity and the acquisition price of used products is known, which is $\tilde{R}_{i}\left(\operatorname{Pr}_{i}, u_{i}\right)=R\left(\operatorname{Pr}_{i}\right)+u_{i}$. Where $\operatorname{Pr}_{i}$ is the acquisition price of used product $i$; $R\left(\operatorname{Pr}_{i}\right)=a_{i}+b_{i} \operatorname{Pr}_{i}$ is the expected return quantity of used product $i\left(a_{i} \geq 0\right.$ and $\left.b_{i}>0\right)$; $u_{i}$ is a random return defined on the range $\left[A_{i}, B_{i}\right]$ with mean $\mu_{i}^{r}$ and standard deviation $\sigma_{i}^{r}$. In this paper, $\mu_{i}^{r}=0, A_{i}=-\infty$, and $B_{i}=+\infty$.

- The remanufacturing costs do not include the cost used to buy back the used products, but 
include the costs for dismantling, inspection, quality assurance, repairing, remanufacturing, components used to replace the worn out ones and other management costs. For the purpose of model development, a sum of such costs is assumed as the remanufacturing cost.

- Similarly, a sum of the costs related with the manufacturing brand-new products is assumed to be the production cost, including all the material and components cost, manufacturing and other management costs.

- Only single period is considered here, therefore the demand and the return are assumed to be independent identically distributed (Inderfurth and Van Der Laan 2001).

For the quality of used product returns, there are usually two kinds of assumptions: one is to assume that all the returns are remanufacturable, such as Van Der Laan et al. 1999, Liang et al. (2009); and the other is to assume that certain percentage of returns can be remanufactured, like Geyer R. (2007), Kim et al. (2006). Here we adapt the former assumption, but our model can be applied to the later assumption through linear transformation of some parameters related with recycle.

The linear price-sensitive return has been applied in Bakal and Akcali (2006), in which the recycling price may be negative or positive depending on the final properties of the used products. Since we assume the manufacturer only acquires the remanufacturable products, the recycling price should be positive in this paper.

\subsection{Model formulation}

The following notations are used in the formulation of the multi-product production planning problem.

\section{Indices:}

$i=1, \ldots, I$ : index of products.

\section{Parameters:}

$p_{i}=$ the selling price of product $i$

$s_{i}=$ the unit overstocking cost of product $i$

$g_{i}=$ the unit understocking cost of product $i$

$c p_{i}=$ the unit production cost of brand-new product $i$ 
$c r_{i}=$ the unit remanufacturing cost of returned product $i$, which usually is much less than $c p_{i}$ $v r_{i}=$ the unit understocking cost of returned product $i$

$h r_{i}=$ the unit overstocking cost of returned product $i$

$m s_{i}=$ the unit resource consumed for producing product $i$

$r s_{i}=$ the unit resource consumed for remanufacturing used product $i$, which is less than $m s_{i}$ $P C=$ the resource capacity of the flexible facility

$f_{i}^{d}(\cdot), F_{i}^{d}(\cdot)=$ pdf and cdf of the distribution of the demand $D_{i}$ for product $i$

$\mu_{i}^{d}=$ the mean of demand for product $i$

$\sigma_{i}^{d}=$ the standard deviation of demand for product $i$

$f_{i}^{r}(\cdot), F_{i}^{r}(\cdot)=$ pdf and cdf of the distribution of the random return $u_{i}$ for product $i$

$\mu_{i}^{r}=$ the mean of the random return $u_{i}$

$\sigma_{i}^{r}=$ the standard deviation of the random return $u_{i}$.

\section{Variables:}

$Q_{i}=$ the total production quantity of product $i$.

$X p_{i}=$ the production quantity of brand-new product $i$.

$\operatorname{Pr}_{i}=$ the unit acquisition price of used product $i$.

$X r_{i}=$ the remanufactured quantity of used product $i$.

To formulate the problem, we first present the formulation to evaluate the remanufacturing cost under return uncertainty. At the beginning of the period, the manufacturer determines the remanufactured quantities and the recycling prices of used products. If the actual return quantity of used product $i$ is less than the expected return quantity, there is understocking cost incurred:, the manufacturer has to make an emergency call either to acquire used products from other areas or to order new components to compensate the shortage so as to keep the production planning. Assume the unit acquisition cost for the understocking product $i$ is $v r_{i}$, then a total remanufacturing and acquisition cost for per unit understocking product $i$ is $v r_{i}+c r_{i}$. Usually, we have $v r_{i}+c r_{i}>c p_{i}$.

If the actual return quantity of is more than the expected quantity, there are overstocking costs for the unremanufactured products. The unit overstocking cost of used product $i, h r_{i}$, includes the inventory cost, the value lost, and some other costs related with disposal of the used product $i$.

Therefore, the total remanufacturing cost of used product $i$ can be formulated as follows: 


$$
R C_{i}\left(X r_{i}, \operatorname{Pr}_{i}\right)= \begin{cases}\left(c r_{i}+\operatorname{Pr}_{i}\right) \tilde{R}_{i}\left(\operatorname{Pr}_{i}, u_{i}\right)+\left(c r_{i}+v r_{i}\right)\left[X r_{i}-\tilde{R}_{i}\left(\operatorname{Pr}_{i}, u_{i}\right)\right] & \tilde{R}_{i}\left(\operatorname{Pr}_{i}, u_{i}\right) \leq X r_{i}, \\ c r_{i} X r_{i}+\operatorname{Pr}_{i} \tilde{R}_{i}\left(\operatorname{Pr}_{i}, u_{i}\right)+h r_{i}\left[\tilde{R}_{i}\left(\operatorname{Pr}_{i}, u_{i}\right)-X r_{i}\right] & \tilde{R}_{i}\left(\operatorname{Pr}_{i}, u_{i}\right) \geq X r_{i} .\end{cases}
$$

Following Petruzzi and Dada (1999), we introduce a new variable $z_{i}=X r_{i}-R\left(\operatorname{Pr}_{i}\right)$, substitute into the above function, then we have

$$
R C_{i}\left(z_{i}, \operatorname{Pr}_{i}\right)= \begin{cases}\left(c r_{i}+\operatorname{Pr}_{i}\right)\left(a_{i}+b_{i} \operatorname{Pr}_{i}+u_{i}\right)+\left(c r_{i}+v r_{i}\right)\left(z_{i}-u_{i}\right), & u_{i} \leq z_{i}, \\ c r_{i}\left(a_{i}+b_{i} \operatorname{Pr}_{i}+z_{i}\right)+\operatorname{Pr}_{i}\left(a_{i}+b_{i} \operatorname{Pr}_{i}+u_{i}\right)+h r_{i}\left(u_{i}-z_{i}\right), & u_{i} \geq z_{i} .\end{cases}
$$

The introduction of the variable $z_{i}$ facilitates the modeling and subsequent analysis, and provides a straightforward interpretation on the remanufacturing decision: there is a shortage for used product $i$ if $z_{i}<u_{i}$; there is overstock if $z_{i}>u_{i}$.

Then the expected remanufacturing cost for product $i$ is expressed as follows:

$$
\begin{aligned}
E R C_{i}\left(z_{i}, \operatorname{Pr}_{i}\right)= & \int_{A_{i}}^{z_{i}}\left[\left(c r_{i}+\operatorname{Pr}_{i}\right)\left(a_{i}+b_{i} \operatorname{Pr}_{i}+u_{i}\right)+\left(c r_{i}+v r_{i}\right)\left(z_{i}-u_{i}\right)\right] f_{i}^{r}\left(u_{i}\right) d u_{i} \\
& +\int_{z_{i}}^{B_{i}}\left[c r_{i}\left(a_{i}+b_{i} \operatorname{Pr}_{i}+z_{i}\right)+\operatorname{Pr}_{i}\left(a_{i}+b_{i} \operatorname{Pr}_{i}+u_{i}\right)+h r_{i}\left(u_{i}-z_{i}\right)\right] f_{i}^{r}\left(u_{i}\right) d u_{i} \\
& =c r_{i}\left(a_{i}+b_{i} \operatorname{Pr}_{i}+z_{i}\right)+\operatorname{Pr}_{i}\left(a_{i}+b_{i} \operatorname{Pr}_{i}+\mu_{i}^{r}\right) \\
& +\int_{A_{i}}^{z_{i}} v r_{i}\left(z_{i}-u_{i}\right) f_{i}^{r}\left(u_{i}\right) d u_{i}+\int_{z_{i}}^{B_{i}} h r_{i}\left(u_{i}-z_{i}\right) f_{i}^{r}\left(u_{i}\right) d u_{i} .
\end{aligned}
$$

Thus, the model for the production planning problem for the closed loop system can be formulated as follows:

$\operatorname{Max}$

$$
\begin{aligned}
E \Pi= & \sum_{i=1}^{I}\left\{\int_{0}^{Q_{i}}\left[p_{i} D_{i}-s_{i}\left(Q_{i}-D_{i}\right)\right] f_{i}^{d}\left(D_{i}\right) d D_{i}+\int_{Q_{i}}^{\infty}\left[p_{i} Q_{i}-g_{i}\left(D_{i}-Q_{i}\right)\right] f_{i}^{d}\left(D_{i}\right) d D_{i}\right\} \\
& -\sum_{i=1}^{I} c p_{i} X p_{i}-\sum_{i=1}^{I} c r_{i}\left(a_{i}+b_{i} \operatorname{Pr}_{i}+z_{i}\right)-\sum_{i=1}^{I} \operatorname{Pr}_{i}\left(a_{i}+b_{i} \operatorname{Pr}_{i}\right) \\
& -\sum_{i=1}^{I} \int_{A_{i}}^{z_{i}} v r_{i}\left(z_{i}-u_{i}\right) f_{i}^{r}\left(u_{i}\right) d u_{i}-\sum_{i=1}^{I} \int_{z_{i}}^{B_{i}} h r_{i}\left(u_{i}-z_{i}\right) f_{i}^{r}\left(u_{i}\right) d u_{i}
\end{aligned}
$$

subject to

$$
\begin{gathered}
\sum_{i=1}^{I} m s_{i} X p_{i}+\sum_{i=1}^{I} r s_{i}\left(a_{i}+b_{i} \operatorname{Pr}_{i}+z_{i}\right) \leq P C \\
Q_{i}=X p_{i}+\left(a_{i}+b_{i} \operatorname{Pr}_{i}+z_{i}\right), \quad \forall i \\
a_{i}+b_{i} \operatorname{Pr}_{i}+z_{i} \geq 0, \quad \forall i \\
A_{i} \leq z_{i} \leq B_{i}, \quad \forall i \\
X p_{i} \geq 0, \operatorname{Pr}_{i} \geq 0, \quad Q_{i} \geq 0, \quad \forall i
\end{gathered}
$$

In the objective function, the first term is the total expected revenue minus the overstock cost 
when the total production quantities are above the actual demand levels. The second term is the total expected revenue minus the understocking cost when the total production quantities are lower than the actual demand levels. The third term is the production cost of brand-new products, and the last four terms are the total expected costs related with recycling and remanufacturing used products.

Constraint (2) is the manufacturer's crucial capacity restriction for manufacturing and remanufacturing processes. Constraints (3) ensure that the total production quantity is equal to the sum of the quantity of brand-new products and the quantity of remanufactured products. Constraints (4) ensure that the quantities of remanufactured products are no less than zero. Constraints (5) restrict the value range of $z_{i}$. Constraints (6) are the nonnegative restrictions.

\section{Solution approach}

The proposed model is a nonlinear programming model, which is difficult to solve, especially for large scale instances. We present a Lagrangian relaxation based approach to obtain near optimal solution for the problem. The approach consists of three phases: first, we construct the Lagrangian relaxation problem by relaxing the capacity constraint (2); second, the Lagrangian relaxation problem is solved by the well-known bisection algorithm. The solution obtained by bisection algorithm may violate constraint (2), although it provides a good upper bound to the original problem. Therefore, in the last phase, a feasibility algorithm is developed to form a feasible solution.

\subsection{Lagrangian Relaxation}

Constraint (2) is relaxed and the relaxed problem is presented below.

$\operatorname{Max}$

$$
\begin{aligned}
L R=\sum_{i=1}^{I} & \left\{\int_{0}^{Q_{i}}\left[p_{i} D_{i}-s_{i}\left(Q_{i}-D_{i}\right)\right] f_{i}^{d}\left(D_{i}\right) d D_{i}+\int_{Q_{i}}^{\infty}\left[p_{i} Q_{i}-g_{i}\left(D_{i}-Q_{i}\right)\right] f_{i}^{d}\left(D_{i}\right) d D_{i}\right\} \\
& -\sum_{i=1}^{I} c p_{i} X p_{i}-\sum_{i=1}^{I} c r_{i}\left(a_{i}+b_{i} \operatorname{Pr}_{i}+z_{i}\right)-\sum_{i=1}^{I} \operatorname{Pr}_{i}\left(a_{i}+b_{i} \operatorname{Pr}_{i}\right) \\
& -\sum_{i=1}^{I} \int_{A_{i}}^{z_{i}} v r_{i}\left(z_{i}-u_{i}\right) f_{i}^{r}\left(u_{i}\right) d u_{i}-\sum_{i=1}^{I} \int_{z_{i}}^{B_{i}} h r_{i}\left(u_{i}-z_{i}\right) f_{i}^{r}\left(u_{i}\right) d u_{i} \\
& +\lambda\left(P C-\sum_{i=1}^{I} m s_{i} X p_{i}-\sum_{i=1}^{I} r s_{i}\left(a_{i}+b_{i} \operatorname{Pr}_{i}+z_{i}\right)\right)
\end{aligned}
$$


subject to (3)-(6).

In the objective function (7), $\lambda$ is the Lagrange multiplier associated with the relaxed constraint (2). Then the relaxed problem can be decomposed into $I$ independent single product subproblems for fixed value of $\lambda$.

\section{Subproblem $L R E_{i}$ :}

$\operatorname{Max}$

$$
\begin{aligned}
L R E_{i}= & \int_{0}^{Q_{i}}\left[p_{i} D_{i}-s_{i}\left(Q_{i}-D_{i}\right)\right] f_{i}^{d}\left(D_{i}\right) d D_{i}+\int_{Q_{i}}^{\infty}\left[p_{i} Q_{i}-g_{i}\left(D_{i}-Q_{i}\right)\right] f_{i}^{d}\left(D_{i}\right) d D_{i} \\
& -\left(c p_{i}+\lambda m s_{i}\right) X p_{i}-\left(c r_{i}+\lambda r s_{i}\right)\left(a_{i}+b_{i} \operatorname{Pr}_{i}+z_{i}\right)-\operatorname{Pr}_{i}\left(a_{i}+b_{i} \operatorname{Pr}_{i}\right) \\
& -\int_{A_{i}}^{z_{i}} v r_{i}\left(z_{i}-u_{i}\right) f_{i}^{r}\left(u_{i}\right) d u_{i}-\int_{z_{i}}^{B_{i}} h r_{i}\left(u_{i}-z_{i}\right) f_{i}^{r}\left(u_{i}\right) d u_{i}
\end{aligned}
$$

Subject to

$$
\begin{gathered}
Q_{i}=X p_{i}+\left(a_{i}+b_{i} \operatorname{Pr}_{i}+z_{i}\right), \\
a_{i}+b_{i} \operatorname{Pr}_{i}+z_{i} \geq 0, \\
A_{i} \leq z_{i} \leq B_{i}, \\
X p_{i} \geq 0, \operatorname{Pr}_{i} \geq 0, \quad Q_{i} \geq 0 .
\end{gathered}
$$

Substitute (8) into (7), then the objective function of the relaxed problem can be written as:

$$
L R=\sum_{i=1}^{I} L R E_{i}+\lambda P C .
$$

\subsubsection{Properties of subproblem $L R E_{i}$}

For any fixed Lagrange multiplier $\lambda$, the relaxed problem can be solved by solving the $I$ single product subproblems $L R E_{i}$.

From constraint (3), we have that $X p_{i}=Q_{i}-\left(a_{i}+b_{i} \operatorname{Pr}_{i}+z_{i}\right)$. Substitute it into function (8), and subproblem $L R E_{i}$ can be reformulated as

$\operatorname{Max}$

$$
\begin{aligned}
\operatorname{LRE}_{i}\left(Q_{i}, \operatorname{Pr}_{i}, z_{i}\right)= & \int_{0}^{Q_{i}}\left[p_{i} D_{i}-s_{i}\left(Q_{i}-D_{i}\right)\right] f_{i}^{d}\left(D_{i}\right) d D_{i}+\int_{Q_{i}}^{\infty}\left[p_{i} Q_{i}-g_{i}\left(D_{i}-Q_{i}\right)\right] f_{i}^{d}\left(D_{i}\right) d D_{i} \\
& -\left(c p_{i}+\lambda m s_{i}\right) Q_{i}+\left[\left(c p_{i}+\lambda m s_{i}\right)-\left(c r_{i}+\lambda r s_{i}\right)\right]\left(a_{i}+b_{i} \operatorname{Pr}_{i}+z_{i}\right)-\operatorname{Pr}_{i}\left(a_{i}+b_{i} \operatorname{Pr}_{i}\right) \\
& -\int_{A_{i}}^{z_{i}} v r_{i}\left(z_{i}-u_{i}\right) f_{i}^{r}\left(u_{i}\right) d u_{i}-\int_{z_{i}}^{B_{i}} h r_{i}\left(u_{i}-z_{i}\right) f_{i}^{r}\left(u_{i}\right) d u_{i}
\end{aligned}
$$

Subject to

$$
a_{i}+b_{i} \operatorname{Pr}_{i}+z_{i} \leq Q_{i}
$$




$$
a_{i}+b_{i} \operatorname{Pr}_{i}+z_{i} \geq 0,
$$

$$
\operatorname{Pr}_{i} \geq 0 \text {. }
$$

Proposition 1: Function $\operatorname{LRE}_{i}\left(Q_{i}, \mathrm{Pr}_{i}, z_{i}\right)$ is concave, and the optimal solutions for maximizing it are

$$
\begin{aligned}
& Q_{i}^{*}=F_{i}^{d^{-1}}\left(\frac{p_{i}+g_{i}-c p_{i}-\lambda m s_{i}}{p_{i}+s_{i}+g_{i}}\right), \operatorname{Pr}_{i}^{*}=\frac{b_{i}\left[\left(c p_{i}+\lambda m s_{i}\right)-\left(c r_{i}+\lambda r s_{i}\right)\right]-a_{i}}{2 b_{i}}, \\
& \text { and } z_{i}^{*}=F_{i}^{r^{-1}}\left(\frac{\left(c p_{i}+\lambda m s_{i}\right)-\left(c r_{i}+\lambda r s_{i}\right)+h r_{i}}{v r_{i}+h r_{i}}\right) .
\end{aligned}
$$

The proof of Proposition 1 is presented in the Appendix.

Proposition 1 provides a way to obtain the optimal solution for function $L R E_{i}\left(Q_{i}, \operatorname{Pr}_{i}, z_{i}\right)$ without considering the constraints (9) and (10). When constraints (9)-(10) are not satisfied, the optimal solution of subprobelm $\operatorname{LRE}_{i}\left(Q_{i}, \operatorname{Pr}_{i}, z_{i}\right)$ is obtained at the bounds since it is concave. If the optimal solution is obtained at $a_{i}+b_{i} \operatorname{Pr}_{i}+z_{i}=Q_{i}$, subproblem $L R E_{i}\left(Q_{i}, \operatorname{Pr}_{i}, z_{i}\right)$ becomes purely remanufacturing problem and the production quantity for brand-new products is zero. If the optimal solution is obtained at $a_{i}+b_{i} \operatorname{Pr}_{i}+z_{i}=0$, subproblem $L R E_{i}\left(Q_{i}, \operatorname{Pr}_{i}, z_{i}\right)$ becomes purely manufacturing problem and the remanufactured quantity is zero.

Proposition 2: For any fixed $Q_{i}$, there are unique $\operatorname{Pr}_{i}^{*}$ and $z_{i}^{*}$ to minimize $L R E_{i}\left(Q_{i}, \operatorname{Pr}_{i}, z_{i}\right)$, which are presented below:

a) If $Q_{i} \geq Q_{i}^{U}$, then $\operatorname{Pr}_{i}^{*}=\frac{b_{i}\left[\left(c p_{i}+\lambda m s_{i}\right)-\left(c r_{i}+\lambda r s_{i}\right)\right]-a_{i}}{2 b_{i}}$,

$$
\text { and } z_{i}^{*}=F_{i}^{r^{-1}}\left(\frac{\left(c p_{i}+\lambda m s_{i}\right)-\left(c r_{i}+\lambda r s_{i}\right)+h r_{i}}{v r_{i}+h r_{i}}\right)
$$

b) If $Q_{i}^{L} \leq Q_{i} \leq Q_{i}^{U}$, then $\operatorname{Pr}_{i}^{*}=\frac{Q_{i}-a_{i}-z_{i}^{0}}{b_{i}}$ and $z^{*}=z_{i}^{0}$;

c) If $0 \leq Q_{i} \leq Q_{i}^{L}$, then $\operatorname{Pr}_{i}^{*}=0$ and $z_{i}^{*}=Q_{i}-a_{i}$.

Where $Q_{i}^{U}=a_{i}+b_{i} \operatorname{Pr}_{i}^{*}+z_{i}^{*}, \quad Q_{i}^{L}=F_{i}^{r^{-1}}\left[\frac{a_{i}+b_{i} h r_{i}}{b_{i}\left(v r_{i}+h r_{i}\right)}\right]+a_{i}$ and $z_{i}^{0}=Q_{i}-a_{i}$. The proof of 
Proposition 2 is presented in the Appendix.

Proposition 2 indicates that there is an upper bound, $Q_{i}^{U}$, for the remanufacturing quantity. If the total production quantity is lower than $Q_{i}^{U}$, the manufacturer would not produce any brand-new products and a purely remanufacturing policy is optimal. Furthermore, if the total production quantity is lower than $Q_{i}^{L}$, the manufacturer has enough returns without any cost to acquire the used products. If the total production quantity is higher than $Q_{i}^{U}$, the manufacturer should produce both brand-new and remanufactured products, i.e., a hybrid manufacturing and remanufacturing policy is optimal. The quantity of remanufactured products should be $Q_{i}^{U}$.

Propositions 1 and 2 provide the way to find optimal production planning for product $i$. For a typical hybrid manufacturing and remanufacturing system, i.e., case a) of Proposition 2, we have the optimal production planning as follows: the optimal production quantity is $Q_{i}^{*}$, which is bigger than $Q_{i}^{U}$ and given by Proposition 1; the optimal remanufactured quantity is $X r_{i}^{*}=a_{i}+b_{i} \operatorname{Pr}_{i}^{*}+z_{i}^{*}$; the optimal production quantity for brand-new products is $X p_{i}^{*}=Q_{i}^{*}-X r_{i}^{*}$. The correspondent acquisition price $z_{i}^{*}$ of the used product $i$ is also given in Proposition 1.

\subsection{Solving the Lagrangian Dual Problem}

We first set $\lambda=0$ and solve subproblems $L R E_{i}$, for $i=1, \ldots, I$, by Proposition 1 . If $\sum_{i=1}^{I} m s_{i} X p_{i}^{*}+\sum_{i=1}^{I} r s_{i} X r_{i}^{*} \leq P C$, it indicates that the capacity constraint (2) is non-operative, and the optimal solutions with $\lambda=0$ are optimal to the original problem. Otherwise, we need to solve the Lagrangian dual problem to find the optimal Lagrange multiplier to minimize the upper bound.

The bisection algorithm is introduced to solve the Lagrangian dual problem. The main process of the algorithm is presented below and its flow chart is shown in Figure 1.

In order to apply the bisection algorithm, we need to find the upper bound and the lower bound for the optimal Lagrange multiplier $\lambda^{*}$. For the lower bound we set $\lambda^{L}=0$. For the upper bound $\lambda^{U}$, we use try and error method: first estimate a value for $\lambda^{U}$; then solve subproblems $L R E_{i}$, for 
$i=1, \ldots, I$, by Propositions 1 and 2, and obtain the optimal production quantities $X r_{i}^{\lambda^{U}}$ and $X p_{i}^{\lambda^{U}}$; if $P C_{\text {error }}=\sum_{i=1}^{I} m s_{i} X p_{i}^{\lambda^{U}}+\sum_{i=1}^{I} r s_{i} X r_{i}^{\lambda^{U}}-P C<0$, the estimated value is the upper bound; otherwise, set $\lambda^{U}=\lambda^{U}+\delta_{0}$ ( $\delta_{0}$ is a small number), recalculate $P C_{\text {error }}$, and repeat this process until we find the value of $\lambda^{U}$ that satisfies $P C_{\text {error }}<0$.

Bisection algorithm for the Lagrangian dual problem:

Step 0: Initialize the problem and set the bounds $\lambda^{L}$ and $\lambda^{U}$ for the Lagrange multiplier.

Step 1: Set $\lambda=\left(\lambda^{L}+\lambda^{U}\right) / 2$. Solve subproblems $L R E_{i}$, for $i=1, \ldots, I$, by Propositions 1 and 2 , and obtain the optimal solutions $\operatorname{Pr}_{i}^{\lambda}, z_{i}^{\lambda}, X r_{i}^{\lambda}, X p_{i}^{\lambda}$ and $Q_{i}^{\lambda}$.

Step 2: Calculate $P C_{\text {error }}=\sum_{i=1}^{I} m s_{i} X p_{i}^{\lambda}+\sum_{i=1}^{I} r s_{i} X r_{i}^{\lambda}-P C$.

Step 3: If $a b s\left(P C_{e r r o r}\right) \leq \delta_{1}$ or $a b s\left(\lambda^{U}-\lambda^{L}\right) \leq \delta_{2}$, then $\lambda^{*}=\left(\lambda^{L}+\lambda^{U}\right) / 2$ and stop.

Step 4: If $P C_{\text {error }}>0$, then set $\lambda^{L}=\lambda$; else set $\lambda^{U}=\lambda$. Go to Step 1 .

In the bisection algorithm, $\delta_{1}$ is a small value that is related to the capacity size, and $\delta_{2}$ is a very small value, such as 0.001 .

\section{[Insert Figure 1 Here]}

\subsection{Feasibility algorithm}

The dual solution obtained by bisection algorithm may violate the capacity constraint (2). We have defined that $P C_{\text {error }}=\sum_{i=1}^{I} m s_{i} X p_{i}^{\lambda *}+\sum_{i=1}^{I} r s_{i} X r_{i}^{\lambda *}-P C$ in the bisection algorithm, where $X p_{i}^{\lambda *}$ and $X r_{i}^{\lambda *}$ are the optimal solutions when $\lambda=\lambda^{*}$. Mostly the bisection algorithm can not find the exact solutions that satisfy $P C_{\text {error }}=0$. If $P C_{\text {error }}>0$, then the solution is infeasible. While $P C_{\text {error }}<0$ implies the capacity is not sufficiently utilized. Hence, we develop a feasibility procedure either to adjust the dual solution to be feasible or to improve the solution. The feasibility algorithm is described as follows.

Step 0: Sort the products in the descending order in terms of unit capacity consuming for manufacturing. 
Step 1: If $P C_{\text {error }}>0$, decrease the production quantities for the products in the order until the total capacity reaches its balance.

Step 2: If $P C_{\text {error }}<0$, increase the production quantities for the products in the reverse order until all capacity is utilized.

The basic idea of the feasibility algorithm is straightforward. Each product has an upper bound on the production quantity, which is the optimal quantity without the capacity limitation. The production quantities adjusted in Step 2 cannot be over their upper bounds. For most of the cases, the balance is reached by adjusting only one product's production quantity because the Lagrangian dual solutions are very near to the optimal.

\section{Computational results and managerial analysis}

The proposed approach is tested on the examples that are randomly produced. All of the algorithms are implemented with MATLAB. The computational experiences for the examples are conducted on the IBM T60 laptop with Windows XP (Intel® Core ${ }^{\mathrm{TM}} 2$ Duo CPU, 1GB of RAM).

\subsection{Numerical example}

In this section, a numerical example is presented to illustrate the closed loop system. The example is based on the examples reflecting a real business situation in Kim et al. (2006) and Rouf $\&$ Zhang (2009). In the system, the manufacturer produces five different types of products. The demands for all five products are assumed to follow normal distributions, and $u_{i}$, for $i=1, \ldots, 5$, also follow normal distributions with mean of zero. The capacity is 32,000. The other parameters of the example are presented in Table 1, and they are estimated by the following procedure: we study the cost structure and the relationship among the parameters of the examples presented in Kim et al. (2006) and Rouf \& Zhang (2009), and then estimate the values of the parameters. Thus, the proposed numerical example can present some insights into the practical hybrid manufacturing and remanufacturing system.

\section{[Insert Table 1 Here]}

The example is solved by the Lagrangian based approach and the solution is presented in Table 2. The optimal profit is $629,741.39$. 
[Insert Table 2 Here]

\subsection{Performance of the solution approach}

In order to test the robustness of the solution approach, twenty problems are randomly produced: ten of them are small size instances that involve 5 products, and the other ten instances are large size that involves 50 products. All instances are solved by the solution approach and the computational results are presented in Table 3.

The gap is defined as (upper bound-lower bound)/lower bound, which is the relative error between the dual bound obtained by the bisection algorithm and the feasible solution obtained by the feasibility algorithm. According to Table 3, the maximal gap for the small size examples is 3.13E-05, while the average gap is $1.02 \mathrm{E}-05$; the maximal gap for the large size examples is 6.79E-06, while the average gap is $2.06 \mathrm{E}-06$. The running time for the large size instances is less than 1 second. In all, we can see that our solution approach can present very good solution to all examples.

[Insert Table 3 Here]

\subsection{Managerial analysis}

In order to gain some insights into the closed loop system, sensitivity analyses are conducted for crucial parameters based on the example presented in Section 5.1.

\section{The production policy versus different capacities}

We observe how the manufacturer's production policy changes under different capacities while the other parameters are fixed. Figure 2 shows that the production quantities for brand-new products increase as the capacity increases. However, the remanufactured quantities decrease as the capacity increase. It seems counter intuitive. Observing that the unit resource consumed for remanufacturing is less than that for manufacturing brand-new products, when the capacity is tighter, the more resource would allocate to remanufacturing to satisfy the demand. When the capacity increases, the manufacturer has more resource to produce brand-new products, instead of offering a high acquisition price for the used product since a high acquisition price would reduce the manufacturer's profit. 
When the capacity is over 36,000 , the production planning keeps unchanged. It indicates that a the manufacturer cannot gain more profit even more capacity is available since the demand is limited.

\section{[Insert Figure 2 Here]}

\section{The used product acquisition policy versus different capacities}

Figure 3 illustrates that when the capacity is less than 36,000 , the recycle prices for acquiring the used products decrease as the capacity increases. The recycle prices keep unchanged when the capacity is over 36,000. According to Proposition 2, the price determines the upper bound of the remanufactured quantity. The variations of the prices shown in Figure 3 are consistent with the changes of the remanufactured quantities in Figure 2.

\section{[Insert Figure 3 Here]}

\section{The production policy versus the demand uncertainty of product 4}

Figure 4 illustrates that the production quantity of brand-new product 4 decreases as the uncertainty of its demand increases, while the production quantities of other brand-new products increases. Figure 5 shows that the remanufactured quantities for all products decrease when the uncertainty of Product 4's demand increases. These two figures indicate that the manufacturer would shift the capacity from the products with high uncertainty to the products with low uncertainty at the situation. They also indicate that the fluctuation of one product's demand uncertainty has an impact on the whole hybrid production policy.

$$
\begin{aligned}
& \text { [Insert Figure } 4 \text { Here] } \\
& \text { [Insert Figure } 5 \text { Here] }
\end{aligned}
$$

\section{The used products acquisition policy versus the uncertainty on demand of product 4}

Figure 6 illustrates that the acquisition prices for all five kinds of used Products decrease when the standard deviation of product 4's demand increases. The changes of the acquisition prices are consistent with that of the remanufactured quantities shown in Figure 5. Figure 6 indicates that the change on the uncertainty of demand for one product impacts the used product acquisition policies for all five products.

[Insert Figure 6 Here] 


\section{Conclusions}

This paper investigates the production planning problem for a multi-product closed loop system. The problem is to determine the production quantities of brand-new products, the remanufactured quantities, and the acquisition prices of the used products simultaneously so as to maximize the manufacturer's total expected profit. There are the two novel ideas in the production planning problem: one is to consider both demand and return uncertainty; the other is to combine the used product acquisition/pricing policy with the manufacturing/remanufacturing planning. We present an integrated mathematical model to formulate the problem. A Lagrangian relaxation based approach is developed to solve the problem.

Twenty numerical examples are randomly produced and used to test the solution approach. Computational results show that our solution approach can obtain near optimal solution to all examples in a very short time. The sensitivity analyses for the capacity illustrates that remanufacturing as a resource-saving strategy is very important to the manufacturer when the resource capacity becomes tighter. The sensitivity analyses for the standard deviation of one product's demand indicates that the fluctuation of a product's demand uncertainty not only impacts the production policy of the product, but also has much influence on the production policies and the used product acquisition policies of all the other products.

The pricing policy for used product is an efficient tool to control the return flow. In this paper, it is assumed that the return is linear price-sensitive. It deserves to investigate how a nonlinear price-sensitive return impacts the production planning. Another extension to this research is to combine the pricing policy of new products with the acquisition policy of used products so as to attain a high balance between the return and the demand.

\section{Acknowledgment}

This research is partially supported by NSERC Discovery grant, CFI funding, and China State Scholarship Fund. We would like to thank the anonymous reviewers for their comments and suggestions that helped improve this paper. 


\section{Appendix}

\section{Proof of Proposition 1.}

The first derivatives to the three variables are as follows:

$$
\begin{aligned}
& \frac{\partial L R E_{i}}{\partial Q_{i}}=p_{i}+g_{i}-c p_{i}-\lambda m s_{i}-\left(p_{i}+s_{i}+g_{i}\right) F_{i}^{d}\left(Q_{i}\right), \\
& \frac{\partial L R E_{i}}{\partial \operatorname{Pr}_{i}}=b_{i}\left[\left(c p_{i}+\lambda m s_{i}\right)-\left(c r_{i}+\lambda r s_{i}\right)\right]-a_{i}-2 b_{i} \operatorname{Pr}_{i}, \\
& \text { and } \frac{\partial L R E_{i}}{\partial z_{i}}=\left(c p_{i}+\lambda m s_{i}\right)-\left(c r_{i}+\lambda r s_{i}\right)+h r_{i}-\left(v r_{i}+h r_{i}\right) F_{i}^{r}\left(z_{i}\right)
\end{aligned}
$$

The second derivatives to the three variables are as follows:

$$
\begin{aligned}
& \frac{\partial^{2} L R E_{i}}{\partial Q_{i}^{2}}=-\left(p_{i}+s_{i}+g_{i}\right) f_{i}^{d}\left(Q_{i}\right), \frac{\partial^{2} L R E_{i}}{\partial \operatorname{Pr}_{i}^{2}}=-2 b_{i} \\
& \text { and } \frac{\partial^{2} L R E_{i}}{\partial z_{i}^{2}}=-\left(v r_{i}+h r_{i}\right) f_{i}^{r}\left(z_{i}\right) .
\end{aligned}
$$

Then the Hessian matrix can be computed:

$$
\begin{aligned}
& H_{1}=\frac{\partial^{2} L R E_{i}}{\partial Q_{i}^{2}}=-\left(p_{i}+s_{i}+g_{i}\right) f_{i}^{d}\left(Q_{i}\right)<0 \\
& H_{2}=\frac{\partial^{2} L R E_{i}}{\partial Q_{i}^{2}} \frac{\partial^{2} L R E_{i}}{\partial \operatorname{Pr}_{i}^{2}}=2 b_{i}\left(p_{i}+s_{i}+g_{i}\right) f_{i}^{d}\left(Q_{i}\right)>0, \\
& \text { and } H_{3}=\frac{\partial^{2} L R E_{i}}{\partial Q_{i}^{2}} \frac{\partial^{2} L R E_{i}}{\partial \operatorname{Pr}_{i}^{2}} \frac{\partial^{2} L R E_{i}}{\partial z_{i}^{2}}=-2 b_{i}\left(p_{i}+s_{i}+g_{i}\right) f_{i}^{d}\left(Q_{i}\right)\left(v r_{i}+h r_{i}\right) f_{i}^{r}\left(z_{i}\right)<0 .
\end{aligned}
$$

Thus, function $\operatorname{LRE}_{i}\left(Q_{i}, \operatorname{Pr}_{i}, z_{i}\right)$ is concave.

The optimal solutions can be obtained by solving $\frac{\partial L R E_{i}}{\partial Q_{i}}=\frac{\partial L R E_{i}}{\partial \operatorname{Pr}_{i}}=\frac{\partial L R E_{i}}{\partial z_{i}}=0$, which are as follows:

$$
\begin{aligned}
& Q_{i}^{*}=F_{i}^{d^{-1}}\left(\frac{p_{i}+g_{i}-c p_{i}-\lambda m s_{i}}{p_{i}+s_{i}+g_{i}}\right), \operatorname{Pr}_{i}^{*}=\frac{b_{i}\left[\left(c p_{i}+\lambda m s_{i}\right)-\left(c r_{i}+\lambda r s_{i}\right)\right]-a_{i}}{2 b_{i}}, \\
& \text { and } z_{i}^{*}=F_{i}^{r^{-1}}\left(\frac{\left(c p_{i}+\lambda m s_{i}\right)-\left(c r_{i}+\lambda r s_{i}\right)+h r_{i}}{v r_{i}+h r_{i}}\right) .
\end{aligned}
$$




\section{Proof of Proposition 2.}

If $Q_{i}$ is fixed, then

$$
\begin{aligned}
& \frac{\partial L R E_{i}}{\partial \operatorname{Pr}_{i}}=b_{i}\left[\left(c p_{i}+\lambda m s_{i}\right)-\left(c r_{i}+\lambda r s_{i}\right)\right]-a_{i}-2 b_{i} \operatorname{Pr}_{i} \\
& \text { and } \frac{\partial L R E_{i}}{\partial z_{i}}=\left(c p_{i}+\lambda m s_{i}\right)-\left(c r_{i}+\lambda r s_{i}\right)+h r_{i}-\left(v r_{i}+h r_{i}\right) F_{i}^{r}\left(z_{i}\right) .
\end{aligned}
$$

The second derivatives to $\operatorname{Pr}_{i}$ and $z_{i}$ are as follows:

$$
\begin{aligned}
& \frac{\partial^{2} L R E_{i}}{\partial \operatorname{Pr}_{i}^{2}}=-2 b_{i} \\
& \text { and } \frac{\partial^{2} L R E_{i}}{\partial z_{i}^{2}}=-\left(v r_{i}+h r_{i}\right) f_{i}^{r}\left(z_{i}\right) .
\end{aligned}
$$

We can know that $\operatorname{LRE}_{i}\left(\operatorname{Pr}_{i}, z_{i}\right)$ is concave.

From $\frac{\partial L R E_{i}}{\partial \operatorname{Pr}_{i}}=\frac{\partial L R E_{i}}{\partial z_{i}}=0$, we can obtain the optimal solution

$$
\operatorname{Pr}_{i}^{*}=\frac{b_{i}\left[\left(c p_{i}+\lambda m s_{i}\right)-\left(c r_{i}+\lambda r s_{i}\right)\right]-a_{i}}{2 b_{i}}, \text { and } z_{i}^{*}=F_{i}^{r^{-1}}\left(\frac{\left(c p_{i}+\lambda m s_{i}\right)-\left(c r_{i}+\lambda r s_{i}\right)+h r_{i}}{v r_{i}+h r_{i}}\right) \text {. }
$$

Let $Q_{i}^{U}=a_{i}+b_{i} \operatorname{Pr}_{i}^{*}+z_{i}^{*}$.

If $Q_{i} \geq Q_{i}^{U}$, then it is the optimal solution; otherwise the optimal solution is obtained at $Q_{i}=a_{i}+b_{i} \operatorname{Pr}_{i}+z_{i}$

Substitute $\operatorname{Pr}_{i}=\frac{Q_{i}-a_{i}-z_{i}}{b_{i}}$ into $\operatorname{LRE}_{i}\left(\operatorname{Pr}_{i}, z_{i}\right)$, then

$$
\begin{aligned}
\operatorname{LRE}_{i}\left[\operatorname{Pr}_{i}\left(z_{i}\right), z_{i}\right]= & \int_{0}^{Q_{i}}\left[p_{i} D_{i}-s_{i}\left(Q_{i}-D_{i}\right)\right] f_{i}^{d}\left(D_{i}\right) d D_{i}+\int_{Q_{i}}^{\infty}\left[p_{i} Q_{i}-g_{i}\left(D_{i}-Q_{i}\right)\right] f_{i}^{d}\left(D_{i}\right) d D_{i} \\
& -\left(c p_{i}+\lambda m s_{i}\right) Q_{i}+\left[\left(c p_{i}+\lambda m s_{i}\right)-\left(c r_{i}+\lambda r s_{i}\right)\right] Q_{i}-\frac{Q_{i}-a_{i}-z_{i}}{b_{i}}\left(Q_{i}-z_{i}\right) \\
& -\int_{A_{i}}^{z_{i}} v r_{i}\left(z_{i}-u_{i}\right) f_{i}^{r}\left(u_{i}\right) d u_{i}-\int_{z_{i}}^{B_{i}} h r_{i}\left(u_{i}-z_{i}\right) f_{i}^{r}\left(u_{i}\right) d u_{i}
\end{aligned}
$$

The first derivative of $\operatorname{LRE}\left[\operatorname{Pr}_{i}\left(z_{i}\right), z_{i}\right]$ is

$$
\frac{d L R E_{i}\left[\operatorname{Pr}_{i}\left(z_{i}\right), z_{i}\right]}{d z_{i}}=-\frac{2 Q_{i}-a}{b_{i}}+\frac{2 z_{i}}{b_{i}}+v r_{i} F_{i}^{r}\left(z_{i}\right)-h r_{i}\left[1-F_{i}^{r}\left(z_{i}\right)\right]
$$


The second derivative of function $\operatorname{LRE}_{i}\left[\operatorname{Pr}_{i}\left(z_{i}\right), z_{i}\right]$ is

$$
\frac{d^{2} L R E_{i}\left[\operatorname{Pr}_{i}\left(z_{i}\right), z_{i}\right]}{d z_{i}^{2}}=\frac{2}{b_{i}}+\left(v r_{i}+h r_{i}\right) f_{i}^{r}\left(z_{i}\right)>0 \text {. }
$$

$\operatorname{LRE}_{i}\left[\operatorname{Pr}_{i}\left(z_{i}\right), z_{i}\right]$ is concave and its optimal solution, $z_{i}^{0}$, can be obtained by solving equation $d L R E_{i}\left[\operatorname{Pr}_{i}\left(z_{i}\right), z_{i}\right] / d z_{i}=0$

Since $\operatorname{Pr}_{i}=\frac{Q_{i}-a_{i}-z_{i}}{b_{i}} \geq 0, \quad z_{i} \leq Q_{i}-a_{i}$.

From function $d L R E_{i}\left[\operatorname{Pr}_{i}\left(z_{i}\right), z_{i}\right] / d z_{i}$, we can see that $z_{i}^{0}$ increases as $Q_{i}$ increases.

Substitute $z_{i}^{0}=Q_{i}-a_{i}$ into $d L R E_{i}\left[\operatorname{Pr}_{i}\left(z_{i}\right), z_{i}\right] / d z_{i}=0$, we can obtain $d L R E_{i}\left[\operatorname{Pr}_{i}\left(z_{i}\right), z_{i}\right] /\left.d z_{i}\right|_{z_{i}^{*}=Q_{i}-a_{i}}=-\frac{a}{b_{i}}+v r_{i} F_{i}^{r}\left(Q_{i}-a_{i}\right)-h r_{i}\left[1-F_{i}^{r}\left(Q_{i}-a_{i}\right)\right]=0$.

Let $Q_{i}^{L}$ denote the unique root for the above equation, then $Q_{i}^{L}=F_{i}^{r^{-1}}\left[\frac{a_{i}+b_{i} h r_{i}}{b_{i}\left(v r_{i}+h r_{i}\right)}\right]+a_{i}$.

Therefore, $z^{*}=z_{i}^{0}$ and $\operatorname{Pr}_{i}^{*}=\frac{Q_{i}-a_{i}-z_{i}^{0}}{b_{i}}$, if $Q_{i} \geq Q_{i}^{L}$; otherwise, $\operatorname{Pr}_{i}^{*}=0$ and $z_{i}^{*}=Q_{i}-a_{i}$.

\section{References}

[1] Aras N., Verter V., Boyaci T. (2006) Coordination and Priority Decisions in Hybrid Manufacturing/Remanufacturing Systems. Production and Operations Management, 15(4): $528-543$

[2] Atasu, A., Çetinkaya, S. (2006) Lot sizing for optimal collection and use of remanufacturable returns over a finite life-cycle, Production and Operations Management, 15 (4): pp. 473-487.

[3] Bakal I.S., Akcali E. (2006) Effects of Random Yield in Remanufacturing with Price-Sensitive Supply and Demand. Production and Operations Management, 15(3): 407-420.

[4] Choi, D.W., Hwang, H., Koh, S.G. (2007) A generalized ordering and recovery policy for reusable items. European Journal of Operational Research, 182(2): 764-774.

[5] Dobos, I., Richter, K. (2006) A production/recycling model with quality consideration. International Journal of Production Economics, 104(2): 571-579. 
[6] Fleischmann, M., Kuik, R., Dekker, R. (2002) Controlling inventories with stochastic item returns: A basic model. European Journal of Operational Research, 138(1): 63-75.

[7] Fleischmann, M., Kuik, R. (2003) On optimal inventory control with independent stochastic item returns. European Journal of Operational Research, 151(1): 25-37.

[8] Georgiadis P., Vlachos D., Tagaras G. (2006) The Impact of Product Lifecycle on Capacity Planning of Closed-Loop Supply Chains with Remanufacturing. Production and Operations Management, 15(4): 514-527.

[9] Geyer R. (2007) The economics of remanufacturing under limited component durability and finite product life cycles. Management Science, 53(1): 88-100.

[10]Guide Jr., V.D.R. (2000) Production planning and control for remanufacturing: industry practice and research needs. Journal of Operations Management, 18(4): 467-483.

[11]Guide Jr VDR, Jayaraman V, Srivastava R, Benton WC. (2000) Supply chain management for recoverable manufacturing systems. Interfaces, 30:125-42.

[12] Guide Jr., V.D.R., Van Wassenhove, L.N. (2001) Managing product returns for remanufacturing. Production and Operations Management, 10 (2): 142-155.

[13]Guide Jr., V.D.R., Teunter, R.H., Van Wassenhove, L.N. (2003) Matching Demand and Supply to Maximize Profits from Remanufacturing. Manufacturing and Service Operations Management, 5(4): 303-316.

[14]Guide V. D. R. Jr., Souza G. C., Van Wassenhove L. N., Blackburn J. D. (2006) Time Value of Commercial Product Returns, Management Science, 52(8): 1200-1214.

[15]Guide Jr., V.D.R., Van Wassenhove, L.N. (2009) The evolution of closed-loop supply chain research. Operations Research, 57(1): 10-18.

[16]Inderfurth, K., Van Der Laan, E. (2001) Leadtime effects and policy improvement for stochastic inventory control with remanufacturing. International Journal of Production Economics, 71(1-3): pp. 381-390.

[17]Inderfurth, K. (2004) Optimal policies in hybrid manufacturing/remanufacturing systems with product substitution. International Journal of Production Economics, 90(3): 325-343.

[18]Inderfurth, K. (2005) Impact of uncertainties on recovery behavior in a remanufacturing environment: A numerical analysis. International Journal of Physical Distribution and Logistics Management, 35(5): 318-336. 
[19]Jayaraman V. (2006) Production planning for closed-loop supply chains with product recovery and reuse: an analytical approach. International Journal of Production Research, 44 (5): 981-998.

[20]Kim, K., Song, I., Kim, J., Jeong, B. (2006) Supply planning model for remanufacturing system in reverse logistics system. Computers \& Industrial Engineering, 51: 279-287.

[21]Liang Y., Pokharel S., Lim GH. (2009) Pricing used products for remanufacturing. European Journal of Operational Research, 193(2): 390-395.

[22]Lieckens K., Vandaele N., (2007) Reverse logistics network design with stochastic lead times, Computers and Operations Research, 34 (2):395-416.

[23]Listes O. A generic stochastic model for supply-and-return network design, Computers and Operations Research, 34 (2): 417-442.

[24]Petruzzi, NC., Dada, M. (1999) Pricing and the newsvendor problem: a review with extensions. Operations Research, 47(2):183-194.

[25]Pokharel, S., Mutha, A. (2009) Perspectives in reverse logistics: a review. Resources, Conservation and Recycling, 53(4): 175-182.

[26]Qu, X., Williams, J.A.S. (2008) An analytical model for reverse automotive production planning and pricing. European Journal of Operational Research, 190(3): 756-767.

[27]Rubio, S., Corominas, A. (2008) Optimal manufacturing-remanufacturing policies in a lean production environment. Computers and Industrial Engineering, 55(1): 234-242.

[28]Rubio S, Chamorro A, Miranda F. (2008) Characteristics of the research on reverse logistics (1995-2005). International Journal of Production Research, 46(4):1099-1120.

[29]Rouf S., Zhang G. (2009) Supply planning for a closed loop system with uncertain demand and return, International Journal of Operational Research, in press.

[30] Van Der Laan, E., Salomon, M., Dekker, R., Van Wassenhove, L. (1999) Inventory control in hybrid systems with remanufacturing. Management Science, 45(5): 733-747.

[31]Zhou L., Naim M.M., Tang Q., Towill Q.R. (2006) Dynamic performance of a hybrid inventory system with a Kanban policy in remanufacturing process. Omega, 34: 585-598. 


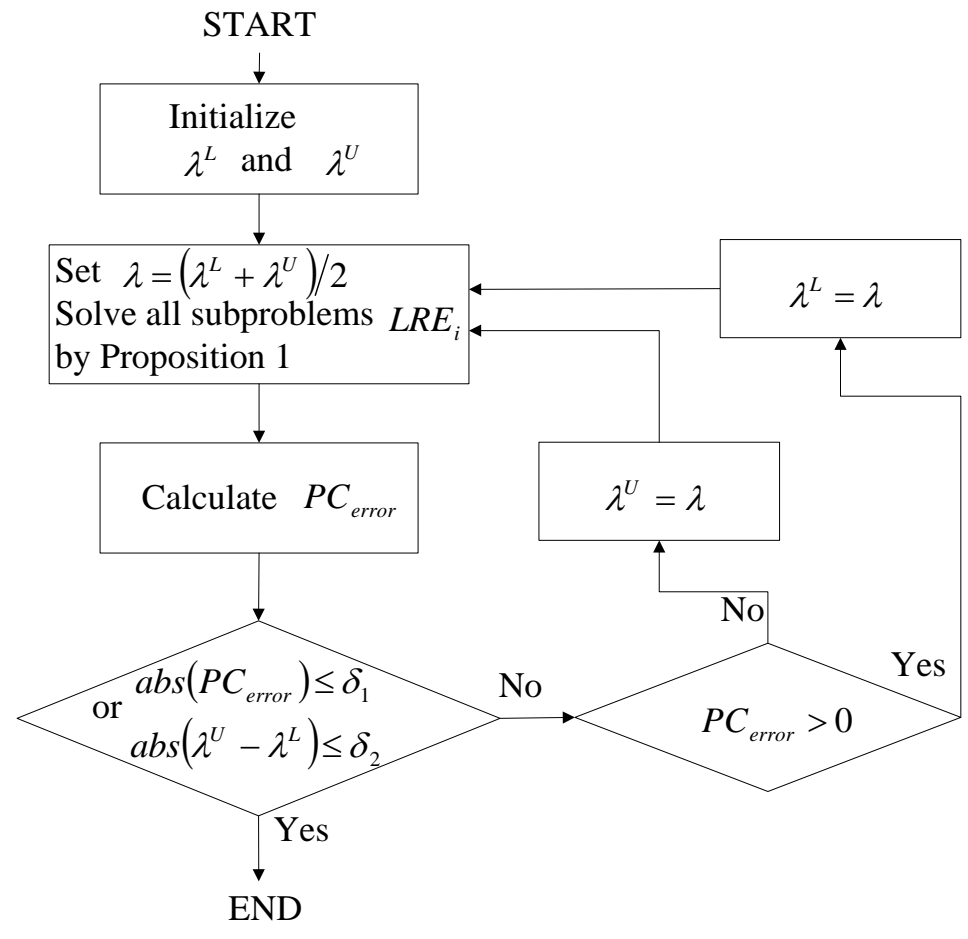

Figure 1. The flow chart of the bisection algorithm 


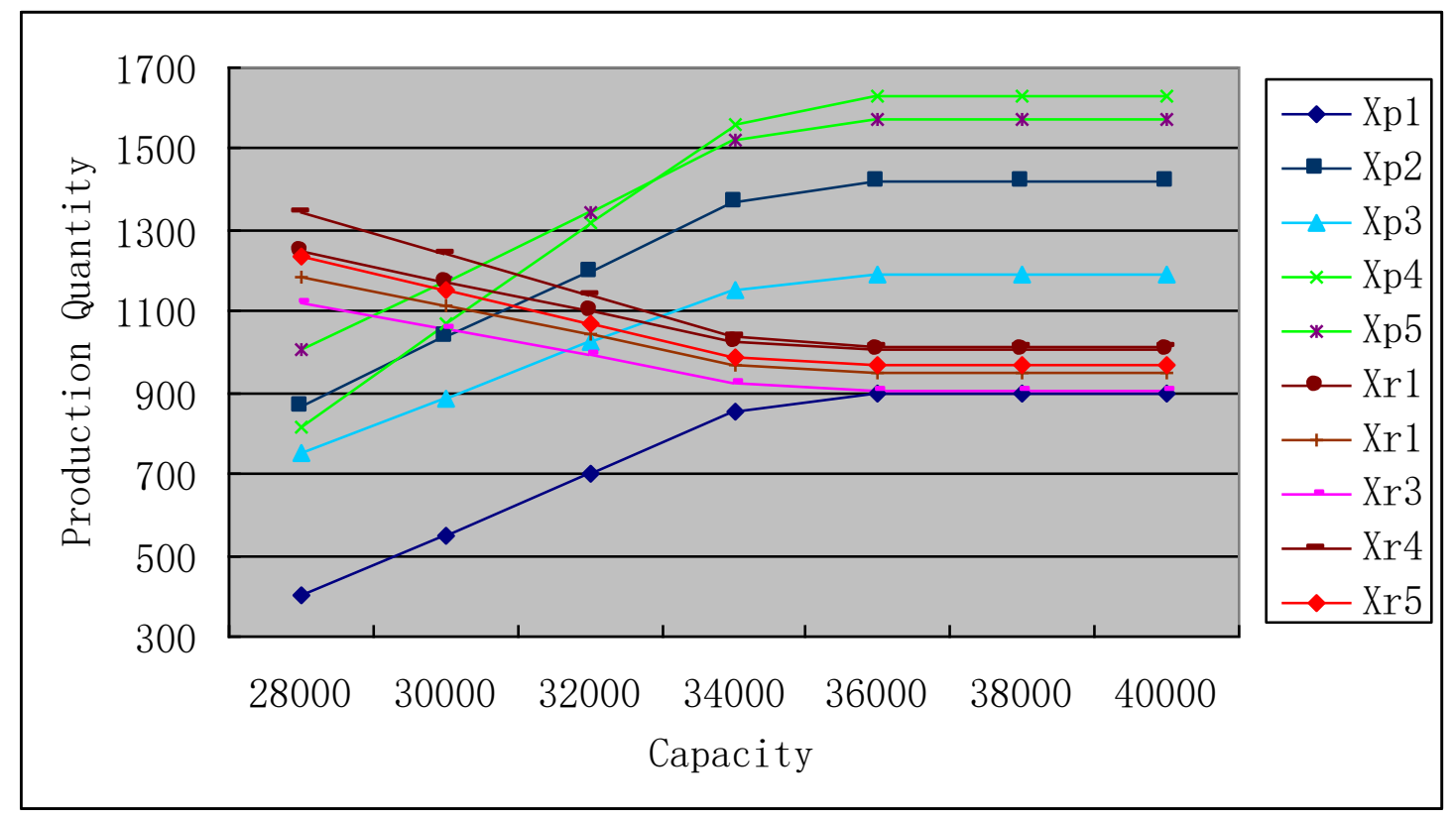

Figure 2. The optimal production policy under different capacities 


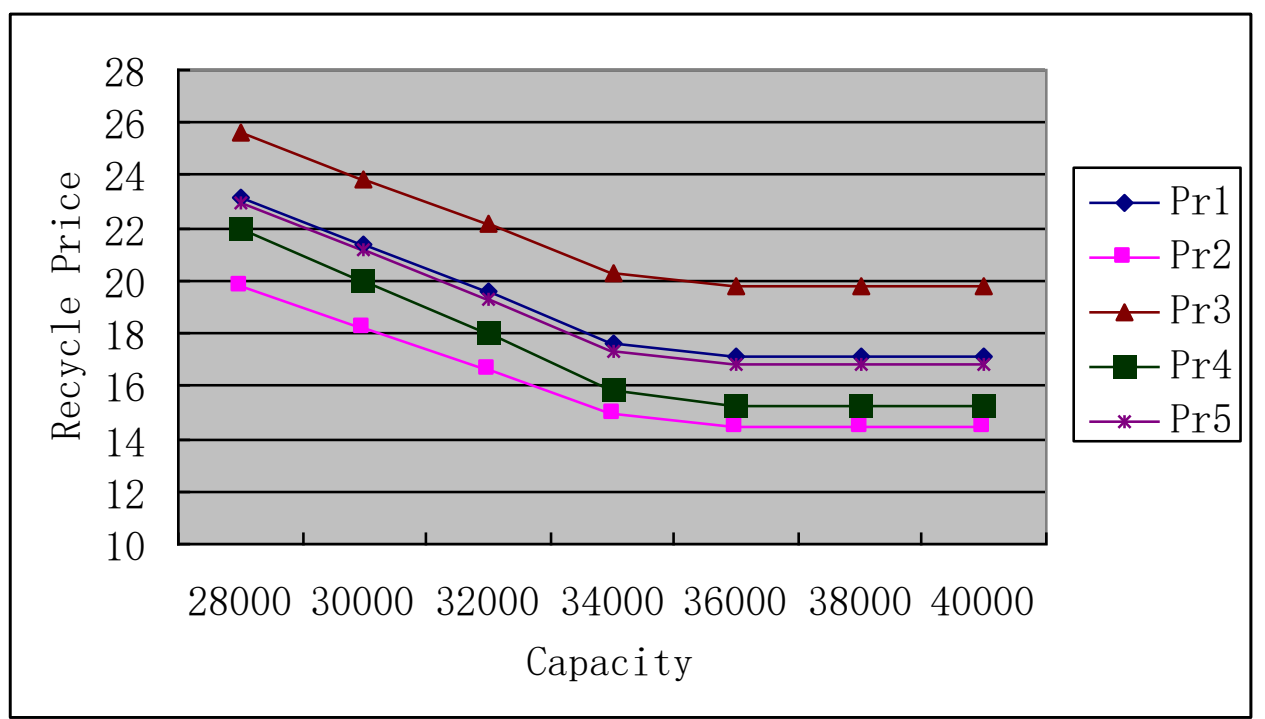

Figure 3. The optimal used product acquisition policy under different capacities 


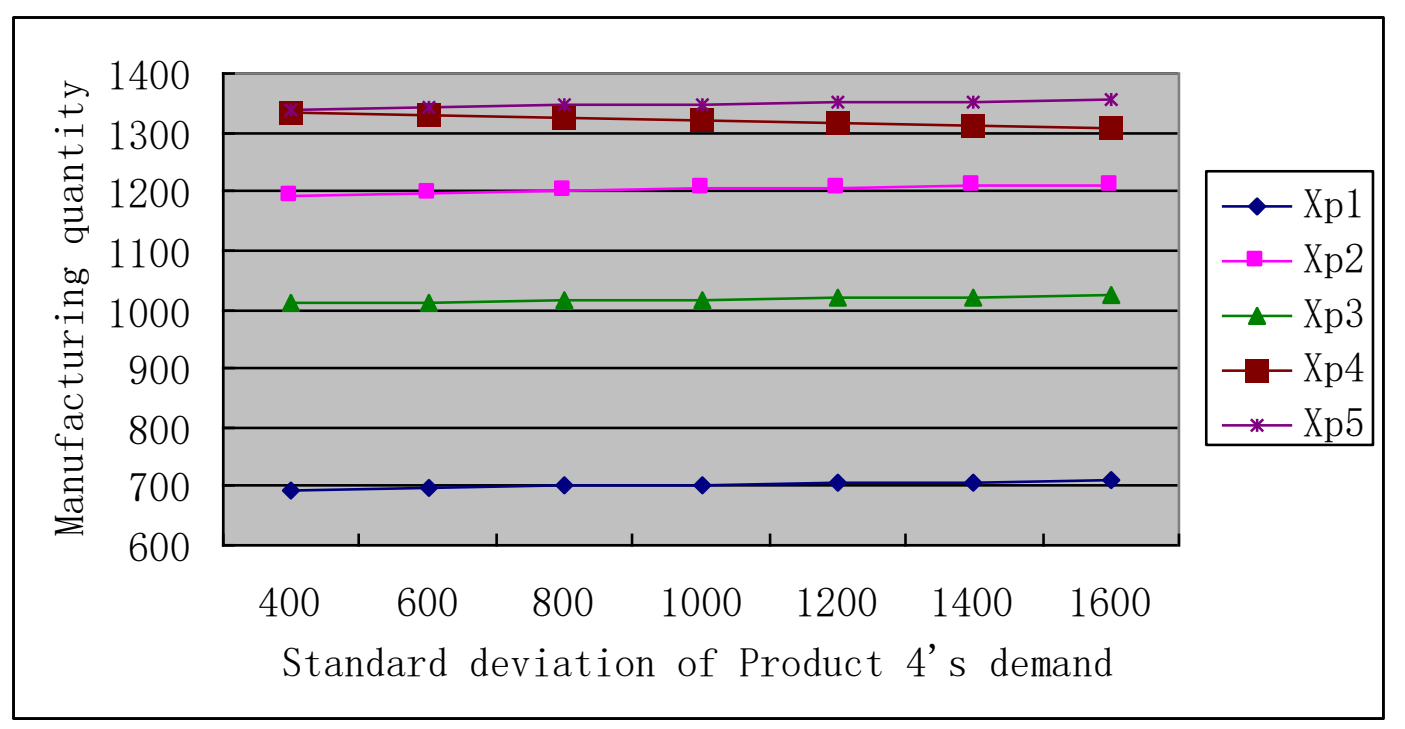

Figure 4. The manufacturing quantities under different standard deviations of Product 4's demand 


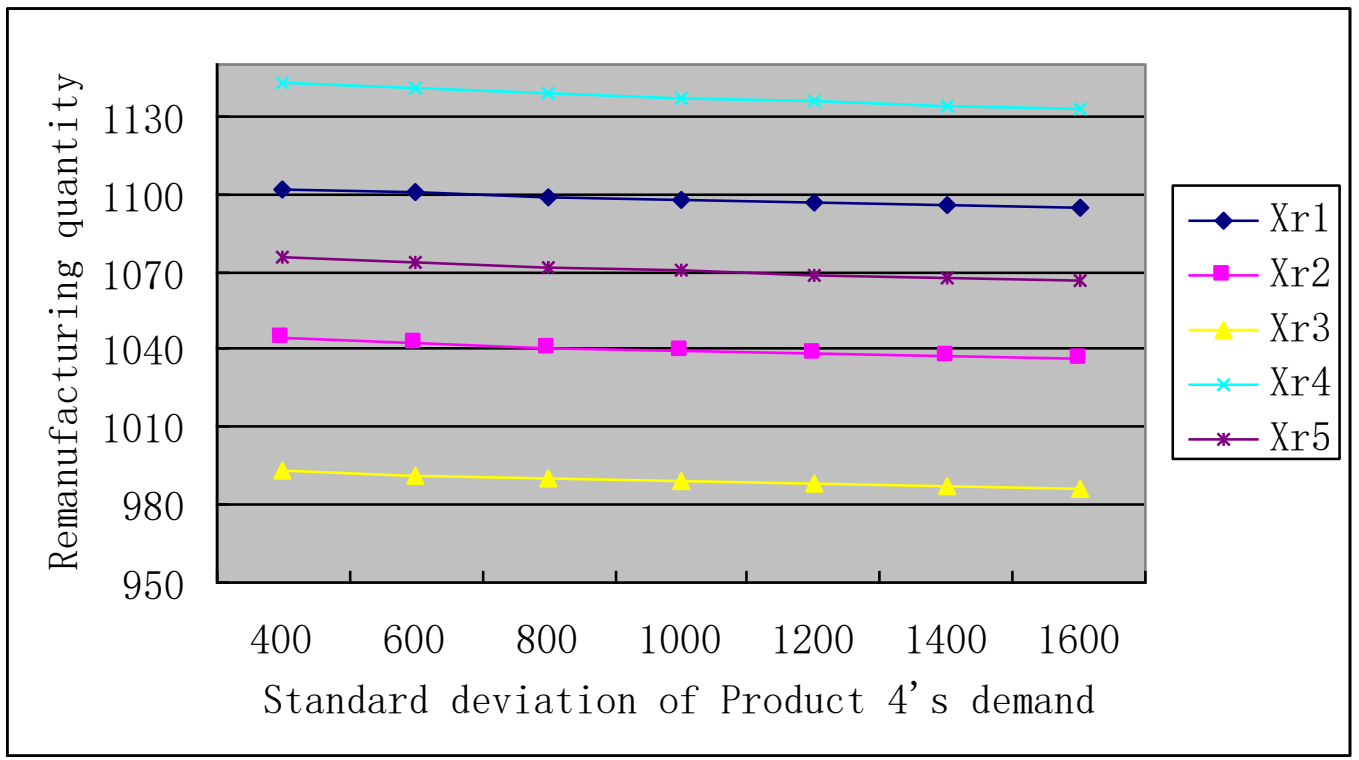

Figure 5. The remanufacturing quantities under different standard deviations of Product 4's demand 


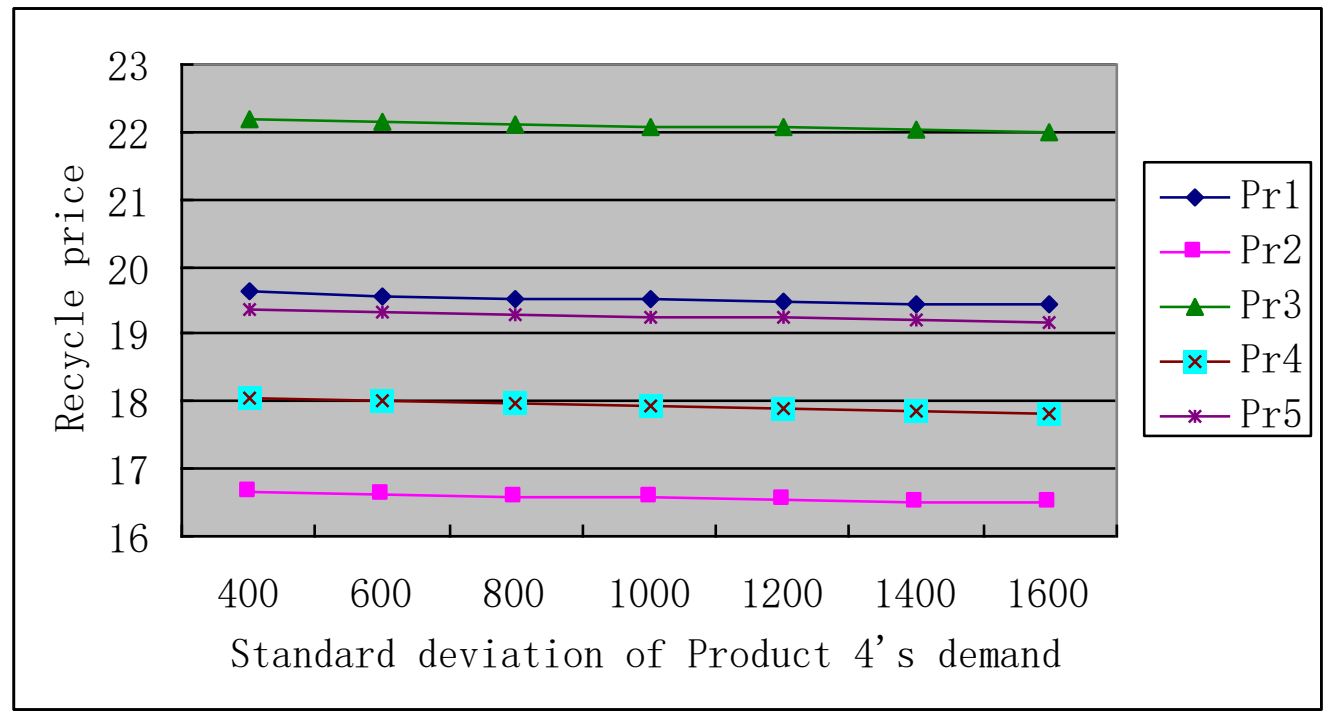

Figure 6. The recycle prices under different standard deviations of Product 4's demand 